\author{
Marquette University \\ e-Publications@Marquette
}

Biomedical Engineering Faculty Research and

Publications

Biomedical Engineering, Department of

$5-2012$

\title{
Robotic Resistance Treadmill Training Improves Locomotor Function in Human Spinal Cord Injury: A Pilot Study
}

\author{
Ming Wu \\ Rehabilitation Institute of Chicago \\ Jill M. Landry \\ Rehabilitation Institute of Chicago \\ Brian Schmit \\ Marquette University, brian.schmit@marquette.edu \\ T. George Hornby \\ Rehabilitation Institute of Chicago \\ Sheng-Che Yen \\ Rehabilitation Institute of Chicago
}

Follow this and additional works at: https://epublications.marquette.edu/bioengin_fac

Part of the Biomedical Engineering and Bioengineering Commons

\section{Recommended Citation}

Wu, Ming; Landry, Jill M.; Schmit, Brian; Hornby, T. George; and Yen, Sheng-Che, "Robotic Resistance Treadmill Training Improves Locomotor Function in Human Spinal Cord Injury: A Pilot Study" (2012). Biomedical Engineering Faculty Research and Publications. 57.

https://epublications.marquette.edu/bioengin_fac/57 
Marquette University

e-Publications@Marquette

\section{Biomedical Engineering Faculty Research and Publications/College of} Engineering

This paper is NOT THE PUBLISHED VERSION; but the author's final, peer-reviewed manuscript. The published version may be accessed by following the link in the citation below.

Archives of Physical Medicine and Rehabilitation, Vol. 93, No. 5 (May 2012): 782-789. DOI. This article is (C) Elsevier and permission has been granted for this version to appear in e-Publications@Marquette. Elsevier does not grant permission for this article to be further copied/distributed or hosted elsewhere without the express permission from Elsevier.

\section{Robotic Resistance Treadmill Training Improves Locomotor Function in Human Spinal Cord Injury: A Pilot Study}

Ming Wu

Sensory Motor Performance Program, Rehabilitation Institute of Chicago, Chicago, IL Department of Physical Medicine and Rehabilitation, Northwestern University Medical School, Chicago, IL

Jill M. Landry

Sensory Motor Performance Program, Rehabilitation Institute of Chicago, Chicago, IL Brian D. Schmit Sensory Motor Performance Program, Rehabilitation Institute of Chicago, Chicago, IL Department of Physical Medicine and Rehabilitation, Northwestern University Medical School, Chicago, IL

Department of Biomedical Engineering, Marquette University, Milwaukee, WI

T. George Hornby

Sensory Motor Performance Program, Rehabilitation Institute of Chicago, Chicago, IL 
Department of Physical Medicine and Rehabilitation, Northwestern University Medical School, Chicago, IL

Department of Physical Therapy, University of Illinois at Chicago, Chicago, IL

Sheng-Che Yen

Sensory Motor Performance Program, Rehabilitation Institute of Chicago, Chicago, IL

\section{Abstract}

Wu M, Landry JM, Schmit BD, Hornby TG, Yen S-C. Robotic resistance treadmill training improves locomotor function in human spinal cord injury: a pilot study.

\section{Objective}

To determine whether cable-driven robotic resistance treadmill training can improve locomotor function in humans with incomplete spinal cord injury (SCl).

Design

Repeated assessment of the same patients with crossover design.

\section{Setting}

Research units of rehabilitation hospitals in Chicago.

\section{Participants}

Patients with chronic incomplete $\mathrm{SCl}(\mathrm{N}=10)$ were recruited to participate in this study.

\section{Interventions}

Subjects were randomly assigned to 1 of 2 groups. One group received 4 weeks of assistance training followed by 4 weeks of resistance training, while the other group received 4 weeks of resistance training followed by 4 weeks of assistance training. Locomotor training was provided by using a cable-driven robotic locomotor training system, which is highly backdrivable and compliant, allowing patients the freedom to voluntarily move their legs in a natural gait pattern during body weight supported treadmill training (BWSTT), while providing controlled assistance/resistance forces to the leg during the swing phase of gait.

\section{Main Outcome Measures}

Primary outcome measures were evaluated for each participant before training and after 4 and 8 weeks of training. Primary measures were self-selected and fast overground walking velocity and 6-minute walking distance. Secondary measures included clinical assessments of balance, muscle tone, and strength.

\section{Results}

A significant improvement in walking speed and balance in humans with $\mathrm{SCl}$ was observed after robotic treadmill training using the cable-driven robotic locomotor trainer. There was no significant difference in walking functional gains after resistance versus assistance training, although resistance training was more effective for higher functioning patients.

\section{Conclusions}

Cable-driven robotic resistance training may be used as an adjunct to BWSTT for improving overground walking function in humans with incomplete $\mathrm{SCl}$, particularly for those patients with relatively high function. 


\section{Key Words}

Locomotion, Rehabilitation, Robotics, Spinal cord injuries

\section{List of Abbreviations}

ANOVA analysis of variance

BBS Berg Balance Scale

BWSTT body weight supported treadmill training

CaLT cable-driven robotic locomotor trainer

$\mathrm{SCl}$ spinal cord injury

BODY WEIGHT SUPPORTED treadmill training (BWSTT) with manual assistance given to the legs and the pelvis has been used as a promising rehabilitation method designed to improve motor function and ambulation in people with spinal cord injury (SCI).1, 2, 3, 4, 5 However, while BWSTT has been shown to provide significant improvements in locomotor ability, motor function, and balance for some patients, ${ }^{6}$ it requires considerable involvement of a physical therapist; that is, generally up to 3 therapists are required in setting the paretic legs and controlling the trunk movement. In addition, BWSTT is a labor-intensive task for physical therapists, particularly for those patients who require substantial walking assistance.

In order to alleviate the significant physical workload on the physical therapist during BWSTT, several robotic systems have been developed for automating locomotor training in patients with $\mathrm{SCl} .7,8,9$ While current robotic gait training devices may reduce staff requirements and physical demands on the physical therapist, ${ }^{10}$ the functional gains experienced by patients are not greater than those obtained with other training modalities, such as treadmill training with manual assistance and overground training. ${ }^{11}$ For instance, results from a randomized study ${ }^{12}$ with patients with chronic $\mathrm{SCl}$ indicated that there were no significant differences in walking speed between the group with robotic gait training and other groups, that is, treadmill training with manual assistance or with electrical stimulation and overground training with electrical stimulation. In particular, only modest functional gains were obtained in walking function (ie, gait speed improved $0.01 \pm 0.05 \mathrm{~m} / \mathrm{s}$ ) after robotic training using a fixed trajectory control strategy. As a consequence, there is a need to improve current robotic-assisted BWSTT methods.

Recently, a novel cable-driven robotic gait training system has been developed. ${ }^{13}$ This device has a number of advantages over previously used devices. By its design, the cable-driven robotic locomotor trainer (CaLT) allows for kinematic error, which drives motor learning.14, 15 The CaLT can also provide controlled forces to the limb during the swing phase of gait in order to produce an optimal training paradigm with either assistance or resistance. ${ }^{16}$ Hypothetically, assistance training could be used to enable stepping on a treadmill, or stepping at a higher speed than would be available otherwise. Resistance training might prove useful for aiding training in stronger patients, in whom resistance to swing could be used to improve swing deficits. The purpose of the current study was to test whether robotic resistance training could improve locomotor function in humans with $\mathrm{SCl}$.

\section{Methods}

\section{Subjects}

Ten individuals with chronic incomplete $\mathrm{SCl}$ (ie, $>12$ mo postinjury) with an injury level ranging from $\mathrm{C} 2$ to $\mathrm{T} 10$ were recruited to participate in this study (table 1). Their mean age \pm SD at the time of study enrollment was 47.0 \pm 7.0 years. The mean interval \pm SD between $\mathrm{SCl}$ and the onset of robotic BWSTT was $5.8 \pm 3.8$ years (range, 1-14y). All subjects were classified by the American Spinal Injury Association Impairment Scale as grade D. 
Specific inclusion criteria for participation in the study included (1) age between 16 and 65 years; (2) medically stable with medical clearance to participate; (3) level of SCI lesion between C2 and T10; (4) passive range of motion of the legs within functional limits of ambulation (ie, ankle dorsiflexion to neutral position, knee flexion from $0^{\circ}$ to $120^{\circ}$, and hip to $90^{\circ}$ flexion and $10^{\circ}$ extension); (5) ability to walk on a treadmill for greater than 30 minutes with partial body weight support as needed; and (6) ability to stand and walk ( $>10 \mathrm{~m})$ without physical assistance with the use of assistive devices or with orthotics that do not cross the knee.

Table 1. Subject Information Indicating Age, Injury Level, AIS Grade, Years Since Injury, WISCI Score, Sex, and Medications the Subjects were Prescribed at the Time of the Study

\begin{tabular}{|l|l|l|l|l|l|l|l|l|}
\hline Subject & $\begin{array}{l}\text { Age } \\
\text { (y) }\end{array}$ & $\begin{array}{l}\text { Time } \\
\text { Postinjury (y) }\end{array}$ & $\begin{array}{l}\text { Injury } \\
\text { Level }\end{array}$ & $\begin{array}{l}\text { AIS } \\
\text { Grade }\end{array}$ & $\begin{array}{l}\text { Assistive } \\
\text { Device }\end{array}$ & $\begin{array}{l}\text { WISCl } \\
\text { Score }\end{array}$ & Sex & Medicine \\
\hline A & 43 & 1.3 & C5-6 & D & None & 20 & M & $\begin{array}{l}\text { Diazepam and } \\
\text { baclofen }\end{array}$ \\
\hline B & 46 & 13.5 & C5-7 & D & None & 20 & M & None \\
\hline C & 53 & 8.9 & C6 & D & None & 20 & M & None \\
\hline D & 34 & 2.5 & C6-7 & D & Cane (AFO) & 19 & M & Tizanidine 2mg \\
\hline E & 48 & 3.3 & T5-7 & D & Rolling walker & 13 & F & Tizanidine 2mg \\
\hline F & 58 & 4.3 & C3-4 & D & Rolling walker & 13 & M & Baclofen 10mg \\
\hline G & 40 & 5.7 & T10 & D & Rolling walker & 13 & F & $\begin{array}{l}\text { Baclofen 20mg } \\
\text { Tizanidine 2mg }\end{array}$ \\
\hline H & 52 & 3 & C2-3 & D & Crutches/AFO & 16 & M & None \\
\hline I & 45 & 6.5 & C4-7 & D & None & 20 & M & None \\
\hline J & 51 & 9 & C3-7 & D & Rolling walker & 13 & M & Baclofen 30mg \\
\hline
\end{tabular}

Abbreviations: AFO, ankle-foot orthosis; AIS, American Spinal Injury Association Impairment Scale; F, female; M, male; WISCI, Walking Index for Spinal Cord Injury.

Exclusion criteria included the presence of unhealed decubiti, existing infection, severe cardiovascular and pulmonary disease, concomitant central or peripheral neurologic injury (eg, traumatic head injury or peripheral nerve damage in lower limbs), history of recurrent fractures, and known orthopedic injury to the lower extremities. Subjects receiving pharmacologic treatment for spasticity were included but were requested to maintain their antispastic medication dosage throughout training sessions. All research on human subjects was conducted with authorization of the Northwestern University Institutional Review Board. Participants provided written informed consent before participating in the study.

\section{Apparatus}

A custom-designed cable-driven robotic gait training system (the CaLT) was used in this study. ${ }^{13}$ In brief, controlled forces were applied to the lower legs at the ankle during treadmill stepping. Specifically, 4 nyloncoated stainless steel cables, driven by 4 motors through cable spools and pulleys, were affixed to custom cuffs that were strapped to the legs around the ankles to produce assistance/resistance force (fig 1). Bilateral ankle positions were measured by using 2 custom, 3-dimensional position sensors. The ankle position signals were used by the operator to control the timing and magnitude of applied forces at targeted phases of gait. 


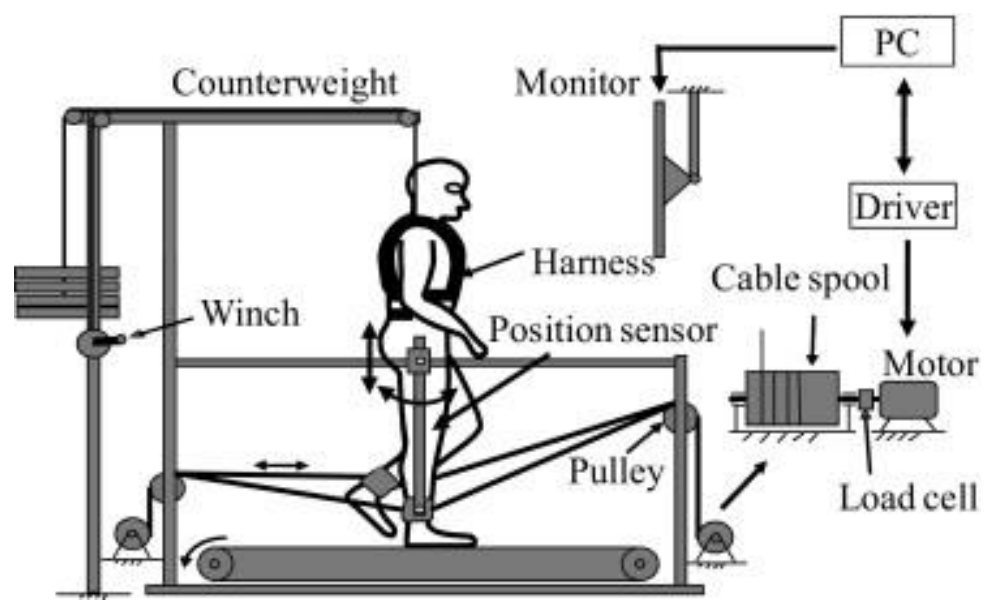

Fig 1. Illustration of the cable-driven robotic gait training apparatus that was used with a treadmill and body weight support system. Four cables driven by 4 motors, pulleys, and cable spools were used to apply controlled resistance/assistance loads during the swing phase of gait. A PC was used to control the coordinated movement of the 4 motors, applying controlled resistance or assistance loads at targeted phase of gait. Abbreviation: PC, personal computer.

\section{Training Protocol}

In order to test the locomotor training effect of the CaLT in the $\mathrm{SCl}$ test group, an 8-week training trial was conducted by using a randomized crossover schedule. Specifically, subjects were randomly assigned to 1 of 2 groups with assistance or resistance training. After the first 4 weeks of training, subjects from both groups were switched from assistance to resistance training or from resistance to assistance training, and then completed another 4 weeks of training. Training was performed 3 times a week for 8 weeks, with the training time for each visit set to 45 minutes as tolerated, excluding setup time. For each training session, subjects were fitted with an overhead harness attached to a counterweight support system, with the counterweight providing as much support as necessary to prohibit knee buckling or toe drag during stepping. Treadmill speed was consistent with maximum comfortable walking speed. At the initiation of locomotor training, controlled assistance (for assistance training group) or resistance (for resistance training group) loads were applied at the ankle of both legs. A physical therapist adjusted the position gains on the basis of the tolerance of the subject. Verbal encouragement and instruction was provided as necessary by a physical therapist during the training. The load amount was automatically controlled by the controller on the basis of the kinematic performance of the subject during treadmill walking. ${ }^{13}$ For the assistance training group, the amount of assistance load was gradually decreased during the course of training. In contrast, for the resistance training group, the amount of resistance load was gradually increased depending on the tolerance of the subject. The amount of body weight support was also gradually decreased and the treadmill speed increased during the course of training on the basis of the tolerance of each subject.

\section{Outcome Measures}

Three assessments of gait were used to determine the training effects. Overground walking speed and endurance, clinical measures of functional ambulation, and static isometric measurements of strength were made at the beginning, the middle (after 4-wk training), and the end of the training period (after 8-wk training). Of these, the primary measures were self-selected and fast walking speed, 6-minute walking distance, ${ }^{17}$ and balance. Overground gait speed data were collected on an instrumented walkway ${ }^{\mathrm{a}}(3.9 \mathrm{~m}$ long and $0.8 \mathrm{~m}$ wide with a 2-m wood walkway extension attached at each end), with exclusion of the acceleration and deceleration distances ( $2 \mathrm{~m}$ at each side). Three trials were conducted for each condition. Balance was measured by using the Berg Balance Scale (BBS). ${ }^{18}$ Secondary outcome measures included clinical assessment and strength tests. 
Specifically, muscle tone, or spasticity, of the major hip and knee muscle groups was assessed clinically by using the Modified Ashworth Scale. ${ }^{19}$ The Walking Index for Spinal Cord Injury-II was used to determine subjects' ambulatory capacity. ${ }^{20}$ Lower-extremity motor scores were also assessed for both lower extremities. ${ }^{21}$ Maximum voluntary isometric joint torques of the hip, knee, and ankle joints were tested by using a 6 degree-of-freedom load cell, ${ }^{\mathrm{b}}$ which was affixed to the output axis of the motor of a Biodex Rehabilitation/Testing System. ${ }^{c}$ Subjective assessments also included the physical component summary score of the Medical Outcomes Study 36-Item Short-Form Health Survey ${ }^{22}$ and score of the Activities-specific Balance Confidence Scale. ${ }^{23}$

\section{Data Analysis}

Data from all subjects were analyzed by using scores before and after 4 and 8 weeks of training. Data for only those subjects who completed all training and evaluation sessions were used for analysis. Overground gait speed and endurance (6-min walk) were analyzed by using repeated-measures analyses of variance (ANOVAs) for the effect of training (pre- vs posttraining), with significance noted at $P<.05$. In addition, improvement in balance (BBS) and other clinical assessments was analyzed by using repeated-measures ANOVAs, with significance noted at $P<.05$. Isometric peak torques of each joint were averaged across the 3 trials and both legs. The rate of torque development was calculated by using the torque increase from $20 \%$ to $80 \%$ peak torque divided by the time intervals to generate this torque increase. A correlation analysis was conducted between functional gains in selfselected gait speed and rate of torque development. A Pearson correlation coefficient was identified. Significance was tested at $\alpha=.05$. Functional gains obtained following resistance and assistance load training were also compared by using ANOVAs, with significance noted at $P<.05$.

\section{Results}

Ten subjects with chronic $\mathrm{SCl}(>12 \mathrm{mo})$ were recruited to participate in this pilot study. Six subjects were randomly assigned to the group with resistance training first, followed by assistance training and 4 subjects were assigned to the group with assistance training first, followed by resistance training. For the former group, all 6 subjects completed 8 weeks of training. For the latter group, 2 of the 4 subjects completed robotic training, with 2 subjects dropping out of the study. One subject dropped out because of increasing knee and low back pain after the first 2 weeks of training, and the other dropped because of difficulty with transportation to the study site. Thus, a total of 8 of the 10 subjects finished 8 weeks of robotic treadmill training ( $80 \%$ completion rate). The average gait speed \pm SD of subjects who completed the study was similar to those of subjects who did not complete the study (ie, $0.67 \pm 0.20$ vs $0.71 \pm 0.28 \mathrm{~m} / \mathrm{s}$ ). The data from only those subjects who completed all the training and evaluation sessions were analyzed.

Across the 8-week training period, the average training time \pm SD increased from $41.3 \pm 6.1$ minutes at the first training session to $44.7 \pm 1.1$ minutes at the last training session. The average training distance \pm SD increased from $1.68 \pm 0.64 \mathrm{~km}$ at the first training session to $2.27 \pm 0.65 \mathrm{~km}$ at the last training session. The average training speed $\pm S D$ increased from $0.71 \pm 0.24 \mathrm{~m} / \mathrm{s}$ at the first training session to $0.92 \pm 0.25 \mathrm{~m} / \mathrm{s}$ at the last training session. In addition, body weight support \pm SD decreased from $23.8 \% \pm 4.3 \%$ at the first training session to $14.3 \% \pm 9.9 \%$ at the last training session.

The CaLT was effective for BWSTT across the training period. For the 8 patients who finished 8 weeks of robotic gait training, we found a significant improvement in self-selected overground walking speed (1-way repeatedmeasures ANOVA, $P=.03$ ); that is, mean gait speed \pm SD improved from $0.67 \pm 0.20$ to $0.76 \pm 0.23 \mathrm{~m} / \mathrm{s}$ (fig $2 \mathrm{~A}$ ). Mean fast walking speed \pm SD also improved from $0.96 \pm 0.31$ to $1.06 \pm 0.32 \mathrm{~m} / \mathrm{s}$, although no significant difference was obtained because of the small sample size $(P=.19)$ (see fig $2 B$ ). In addition, mean scores \pm SD on the BBS significantly improved from $42 \pm 12$ at pretraining to $45 \pm 12$ after 8 weeks of robotic gait training (see fig $2 C$ ). There were no significant changes in walking distance before and after robotic training evaluation sessions 
$(P=.12)$, although the average 6 -minute walk distance \pm SD increased from $223 \pm 81 \mathrm{~m}$ at pretraining to $247 \pm 88 \mathrm{~m}$ at posttraining (see fig 2D).
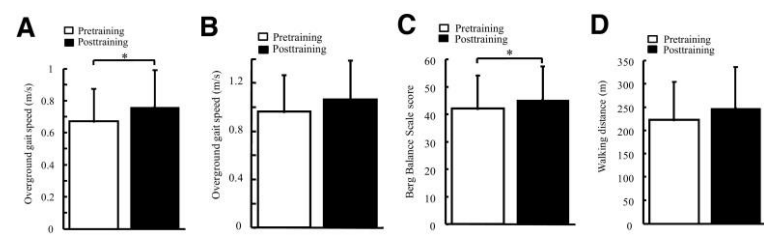

Fig 2. Self-selected (A) and fast (B) overground walking speed and BBS score (C) and 6-minute walking distance (D) before and after 8 weeks of robotic treadmill training through the cable-driven robotic gait training system. An instrumented walkway (GaitMat II, E.Q., Inc ${ }^{\mathrm{a}}$ ) was used to measure overground gait speed. Data shown in the figure are mean and SD of gait speed, BBS score, and walking distance across subjects. ${ }^{*} P<.05$.

The spatial-temporal parameters of gait changed following robotic training. Specifically, stride length, step length, and cadence during self-selected walking significantly improved following robotic training (ANOVA, $P=.02$ for the stride length, $P=.03$ for the step length, and $P=.02$ for the cadence) (table 2). In addition, single leg support time increased $18 \%$ and double leg support time decreased $16 \%$, although the change was not significant ( $P=.06$ for the single leg support time and $P=.15$ for the double leg support time). The spatialtemporal gait parameters during fast walking also changed with similar patterns before and after 8 weeks of robotic gait training, although no significant changes were noted (see table 2). There were no significant changes in muscle strength after robotic training. Specifically, the peak torque and rate of torque development at the hip, knee, and ankle joints had no significant changes, although there was a trend toward an increase in peak torque and rate of torque for hip flexion and ankle plantarflexion (ANOVA, $P>.05$ ) (see table 2 ).

Table 2. Selected Spatiotemporal Gait Parameters, Muscle Strength, and Clinical Measures Before and After 8 Weeks of Robotic Treadmill Training

\begin{tabular}{|l|l|l|l|l|}
\hline Variable (units) & Pretest & Posttest & $\boldsymbol{P}$ & $\boldsymbol{\Delta}(\%)$ \\
\hline Self-selected velocity & & & & \\
\hline Stride length (m) & $1.03 \pm 0.16$ & $1.10 \pm 0.22$ & $.02^{*}$ & 6 \\
\hline Step length (m) & $0.52 \pm 0.09$ & $0.55 \pm 0.11$ & $.03^{*}$ & 6 \\
\hline Cadence (steps/min) & $77 \pm 19$ & $83 \pm 18$ & $.02^{*}$ & 7 \\
\hline Single support (\%) & $27 \pm 9$ & $32 \pm 5$ & .06 & 18 \\
\hline Double support (\%) & $43 \pm 14$ & $36 \pm 9$ & .15 & -16 \\
\hline Fast velocity & & & & \\
\hline Stride length (m) & $1.17 \pm 0.19$ & $1.26 \pm 0.31$ & .06 & 8 \\
\hline Step length (m) & $0.59 \pm 0.11$ & $0.63 \pm 0.16$ & .08 & 8 \\
\hline Cadence (steps/min) & $93 \pm 23$ & $97 \pm 22$ & .29 & 4 \\
\hline Single support (\%) & $32 \pm 14$ & $34 \pm 6$ & .16 & 8 \\
\hline Double support (\%) & $37 \pm 14$ & $32 \pm 8$ & .43 & -11 \\
\hline Lower-extremity motor scores & $45 \pm 4$ & $46 \pm 3$ & .37 & 2 \\
\hline Physical SF-36 score & $34.0 \pm 7.8$ & $39.5 \pm 7.3$ & $.02 *$ & 16 \\
\hline ABC score (\%) & $54.9 \pm 18.5$ & $70.4 \pm 14.2$ & $.01^{*}$ & 28 \\
\hline Modified Ashworth Scale score & & & & \\
\hline Flexor & $0.75 \pm 0.95$ & $0.81 \pm 0.79$ & .82 & 8 \\
\hline Extensor & $1.75 \pm 0.81$ & $1.63 \pm 0.79$ & .55 & -7 \\
\hline Peak torque (Nm) & & & & \\
\hline Hip & & & & \\
\hline Flexion & $41.8 \pm 24.0$ & $46.9 \pm 21.8$ & .23 & 12 \\
\hline Extension & $225.5 \pm 105.6$ & $212.7 \pm 100.3$ & .31 & -6 \\
\hline
\end{tabular}




\begin{tabular}{|l|l|l|l|l|}
\hline Knee & & & & \\
\hline Flexion & $103.2 \pm 43.7$ & $98.6 \pm 42.4$ & .18 & -5 \\
\hline Extension & $166.4 \pm 87.8$ & $164.6 \pm 93.7$ & .80 & -1 \\
\hline Ankle & & & & \\
\hline Dorsiflexion & $37.0 \pm 11.9$ & $36.3 \pm 13.7$ & .71 & -2 \\
\hline Plantarflexion & $96.0 \pm 32.5$ & $103.7 \pm 42.9$ & .28 & 8 \\
\hline Rate of torque $\left(\mathrm{Nm} \cdot \mathrm{s}^{-1}\right)$ & & & & \\
\hline Hip & & & & \\
\hline Flexion & $70.0 \pm 62.8$ & $79.9 \pm 94.4$ & .53 & 14 \\
\hline Extension & $254.8 \pm 227.6$ & $203.6 \pm 208.9$ & .06 & -20 \\
\hline Knee & & & & \\
\hline Flexion & $119.9 \pm 81.0$ & $119.9 \pm 84.0$ & .99 & 0 \\
\hline Extension & $237.9 \pm 155.4$ & $213.3 \pm 133.8$ & .36 & -10 \\
\hline Ankle & & & & \\
\hline Dorsiflexion & $79.4 \pm 26.6$ & $76.8 \pm 36.6$ & .65 & -3 \\
\hline Plantarflexion & $126.2 \pm 70.1$ & $143.1 \pm 78.0$ & .23 & 13 \\
\hline
\end{tabular}

NOTE. Data shown in the table are mean and SD of gait parameters and clinical measures.

Abbreviations: ABC, Activities-specific Balance Confidence; SF-36, Medical Outcomes Study 36-Item Short-Form Health Survey.

*Indicates significant difference.

The rate of torque development was highly correlated with the functional gains observed following robotic treadmill training. Specifically, the rate of torque development of hip flexion/extension, knee flexion/extension, and ankle dorsiflexion/plantarflexion before treadmill training was significantly correlated to the self-selected gait speed changes after robotic training $(P<.05)$ (fig $3 A-C)$. In contrast, the peak torque of hip and knee flexion/extension and ankle dorsiflexion had no significant correlation with gait speed gains (ie, $P=.20$ and $P=.18$ for hip flexion and extension, respectively, $P=.10$ and $P=.06$ for knee flexion and extension, respectively, and $P=.53$ for ankle dorsiflexion), although the peak torque of ankle plantarflexion was significantly correlated with gait speed gains $(P=.025)$.
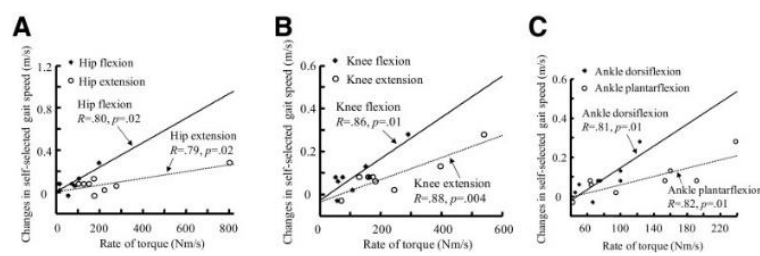

Fig 3. The relation between change in self-selected walking speed and rate of torque development of the hip (A), knee (B), and ankle (C). Rate of torque was averaged across both legs for each individual.

Other clinical assessments had no significant changes before and after robotic treadmill training, except the physical Medical Outcomes Study 36-Item Short-Form Health Survey score and the Activities-specific Balance Confidence Scale score. Specifically, mean lower-extremity motor scores \pm SD slightly increased from $45 \pm 4$ to $46 \pm 3$ after robotic training, although this change was not significant $(P=.37)$. The Modified Ashworth Scale scores had no significant changes following training ( $P=.82$ and $P=.55$ for flexor and extensor, respectively). In addition, we found that all subjects in this study had no change in their mean Walking Index for Spinal Cord Injury-II scores \pm SD before and after robotic treadmill training (17 \pm 4$)$. The mean physical Medical Outcomes Study $36-$ Item Short-Form Health Survey scores and the Activities-specific Balance Confidence Scale score \pm SD significantly increased from $34.0 \pm 7.8$ to $39.5 \pm 7.3(P=.02)$ and from $54.9 \% \pm 18.5 \%$ to $70.4 \% \pm 14.2 \%(P=.01)$, respectively, after robotic training (see table 2 ). 
The CaLT was effective in both assistance and resistance training modes for the subjects in this study. The functional gains obtained following robotic resistance/assistance training showed no significant differences. Specifically, mean self-selected speed \pm SD increased by $.046 \pm .065$ and $.041 \pm .073 \mathrm{~m} / \mathrm{s}$ following resistance and assistance training, respectively, but there was no significant difference between these 2 types of training methods (ANOVA, $P=0.9$ ). However, self-selected speed gains obtained from resistance training were $12 \%$ greater than those obtained from assistance training for the subjects we tested. Mean BBS scores \pm SD increased $2.4 \pm 2.3$ and $0.9 \pm 2.5$ following resistance and assistance training, respectively. There was no significant difference between these training conditions on the balance scores $(P=.35)$, although BBS scores after resistance training were 2.7 times greater than those after assistance training. The mean 6 -minute walk distance \pm SD increased $8.2 \pm 29.5 \mathrm{~m}$ and $16.5 \pm 28.9 \mathrm{~m}$ after resistance and assistance training, respectively, with no significant difference between these 2 training conditions $(P=0.6)$. In addition, the mean fast walking speed \pm SD increased $.03 \pm .11$ and $.07 \pm .12 \mathrm{~m} / \mathrm{s}$ after resistance and assistance training, respectively. There was no significant difference between these 2 types of training methods for fast walking speed $(P=0.3)$.

In addition, we observed a trend that the gains in self-selected gait speed were greater for the higher speed walkers after resistance training (fig 4). In contrast, the gains in self-selected gait speed were greater for slower speed walkers after assistance training. These results suggest that assistance training may be more effective for lower functioning patients but less effective for higher functioning patients. For higher functioning patients, a resistance training paradigm may be more effective to further improve locomotor function.

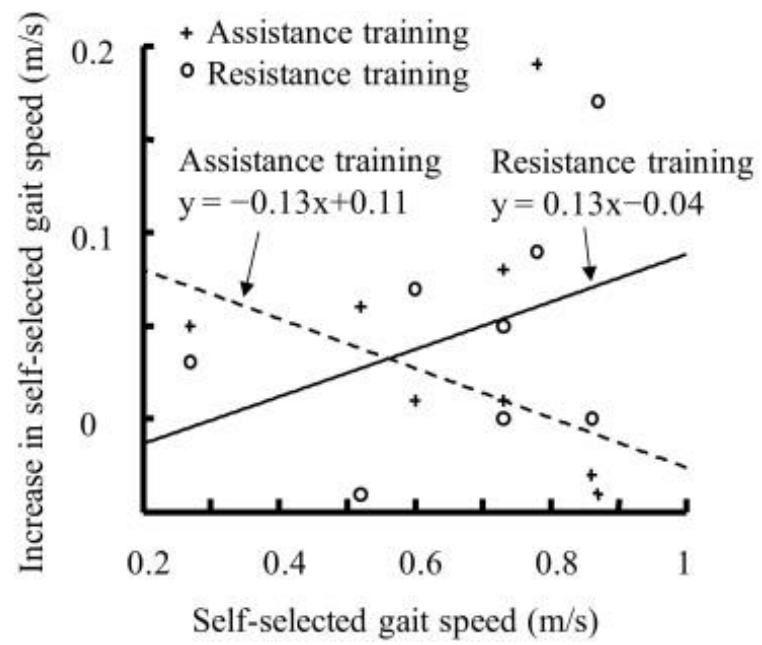

Fig 4. Functional gains in self-selected overground gait speed obtained after 4 weeks of assistance or resistance treadmill training through the cable robot. Linear regression lines are shown in the figure to indicate the relation between functional gains after resistance/assistance training and initial self-selected overground gait speed tested at the start of robotic treadmill training. Specifically, the solid line indicates the relation between the increase in self-selected walking speed after resistance training and the initial speed $(r=.43, P=.28, \mathrm{n}=8)$. The dashed line indicates the relation between the increase in self-selected walking speed after assistance training and the initial speed $(r=-0.7, P=.08, n=7$, data from 1 subject was not included in this linear regression because it was defined as an outlier).

\section{Discussion}

Our primary purpose in this crossover pilot study was to determine whether robotic resistance or assistance treadmill training by using CaLT would be effective in improving ambulatory and functional capabilities of people with chronic motor incomplete $\mathrm{SCl}$. We found that it is feasible to improve locomotor function in people with incomplete $\mathrm{SCl}$ through a flexible cable-driven robotic gait training system, although we did not compare conventional manual BWSTT with CaLT training in the current study. It is still unknown whether the 
improvements with and without CaLT are equivalent, although we would expect the training with CaLT to be at least as good as conventional BWSTT on the basis of results from this study. Particularly, both robotic assistance and resistance training were effective for improving locomotor function in human $\mathrm{SCl}$ with no significant difference between assistance and resistance training groups due to the small sample size (a reliable statistical comparison of the 2 groups with $n=8$ was not possible). Furthermore, different training paradigms may be needed for patients with varying functional levels. For instance, robotic assistance training may be more effective for lower functioning patients to improve their walking capabilities, while a resistance training paradigm may be more effective for higher functioning patients to promote further functional improvement.

Intensive task-specific walking practice was delivered through a cable-driven robotic-assisted BWSTT system to improve locomotor function in humans with $\mathrm{SCl}$. Our results indicate that the improvements in locomotor function in our ambulatory subject population were statistically significant, with self-selected gait speed and BBS scores increasing by $13 \%$ and $7 \%$, respectively, after 8 weeks of robot-assisted treadmill training. In particular, both cadence and stride length increased following robotic training, suggesting an improved gait pattern for people with $\mathrm{SCl}$ after robotic training. These improvements were qualitatively similar to those achieved by people with a similar diagnosis and chronicity of injury who completed therapist-assisted BWSTT. ${ }^{24}$ Thus, cabledriven robotic BWSTT may achieve comparable functional gains when compared with therapist-assisted BWSTT, but it can substantially reduce the labor and personnel cost of physical therapists.

The locomotor functional gains obtained by using the cable-driven robotic gait training system are comparable or even greater than gains reported with currently available robotic systems that provide a fixed trajectory control strategy. For instance, in a recent randomized trial, the use of robotic-assisted BWSTT with a fixed trajectory did not significantly increase walking velocity (mean difference \pm SD was $0.01 \pm 0.05 \mathrm{~m} / \mathrm{s}$ ), ${ }^{12}$ although results from another study indicated that the use of robotic-assisted treadmill training may significantly improve walking speed in the population with $\mathrm{SCl}$ (mean difference $\pm \mathrm{SD}$ was $0.11 \pm 0.11 \mathrm{~m} / \mathrm{s}$ ). ${ }^{25}$

In addition, results from the current study indicate an improvement in balance control in human $\mathrm{SCl}$ after cabledriven robotic gait training. For instance, in the current study, mean BBS scores \pm SD increased $3.3 \pm 2.3$ after robotic training. In contrast, these gains have not been seen for people with $\mathrm{SCl}$ who underwent Lokomat training. A potential explanation for this is that the current Lokomat allows movement only in the sagittal plane because of the limited degrees of freedom. The unnecessary medial-lateral support may reduce potential functional gains in balance control following robotic gait training using the Lokomat. It has been demonstrated that there is a strong relation between balance and walking capacity in patients with $\mathrm{SCl}^{26}$ Thus, training stereotypical gait patterns in human $\mathrm{SCl}$ without challenging balance control may squander training time by focusing training on an impairment that is not the bottleneck for achieving a greater walking speed. ${ }^{27}$

The efficacy of robotic BWSTT may be improved through the active involvement of subjects who undergo treadmill training. This concept is supported by observations that active motor training is more effective than passive training in eliciting performance improvement.28, 29 In this study, an adaptive assistance force or a controlled resistance force was applied to the leg during treadmill training. Thus, subjects were continuously challenged and actively involved during robot-assisted treadmill training. In addition, the highly backdrivable cable-driven robot minimally constrains leg movement and allows for variability in leg kinematics during treadmill walking, ${ }^{13}$ which is suggested to be critical in motor learning.30, 31

While muscle strength has been shown to be critical to locomotor abilities in humans with $\mathrm{SCl},{ }^{32}$ the functional gains in walking speed obtained after robotic training in the current study had no direct correlation with changes in muscle strength. This is consistent with previous studies in which manual muscle assessment was conducted at before and after treadmill training in human $\mathrm{SCl} .25$, 33 Furthermore, results from the current study indicate that the rate of torque development was highly correlated to functional gains following treadmill training. This is 
consistent with stroke studies pertaining to the upper extremity, which show that the rate of torque development correlates more with functional improvement than does muscle strength.34, 35 This suggests that the rate of torque development may be used to predict functional gains following treadmill training. This would be helpful for clinicians to identify patients with $\mathrm{SCl}$ who may experience functional gains with intensive and task-specific gait training interventions.

\section{Study Limitations}

The patients who participated in the current study were all ambulatory subjects with or without an assistive device. It remains unclear whether cable-driven robotic gait training will be effective in improving locomotor function in humans with $\mathrm{SCl}$ who are more severely impaired and are unable to ambulate. The injury level of participants ranged from C2 to T10. Six of the 8 subjects who completed all training and evaluation sessions had an injury at the cervical level. In addition, 3 of the 8 subjects were taking antispastic medications during the training sessions. These factors may have influenced the results of the robotic-assisted treadmill training. ${ }^{36}$ However, because of the small sample size of the current study, we are not able to draw conclusions about the effect of injury level and antispastic medications on locomotor recovery following robotic training in this population. In addition, the subject number in the 2 groups who participated in resistance training first or assistance training first was not matched because of subject dropout, which might impact the results. However, while some subjects had greater improvements in walking speed from the first training period, other subjects did not. The average overground walking speed did not show a plateau pattern across the 8-week training period (overground walking speed was evaluated every $2 \mathrm{wk}$ ) for the subjects who participated in this study. A randomized controlled study is ongoing to determine whether cable-driven robotic-assisted BWSTT can produce greater functional improvements than those achieved through more conventional manual-assisted BWSTT in humans with $\mathrm{SCl}$.

\section{Conclusions}

Cable-driven locomotor training could be used to improve locomotor function in people with incomplete $\mathrm{SCl}$. The cable-driven robotic gait training system is highly backdrivable, is compliant, and allows patients the freedom to voluntarily move their legs during BWSTT. As a result, patients can be actively involved during cabledriven robotic treadmill training, which is critical to improving the efficacy of robotic BWSTT. A controlled resistance load can be applied to the legs during treadmill training as an adjunct to improve locomotor function in human $\mathrm{SCl}$, especially for those subjects with relatively high walking function.

\section{Suppliers}

a. GaitMatt II; E.Q., Inc, P.O. Box 16, Chalfont, PA 18914-0016.

b. Model 3550; ATI Industrial Automation, Inc, 1031 Goodworth Dr, Apex, NC 27539.

c. Biodex Rehabilitation/Testing System; Biodex Medical Systems, Inc, 20 Ramsey Rd, Shirley, NY 119674704.

\section{Acknowledgments}

We thank W. Zev Rymer, MD, PhD, for his support of this project; James Stinear, PhD, for his laboratory support; and Yunhui Zhang, BS, for her assistance with data analysis.

\section{References}

\section{A.L. Behrman, S.J. Harkema. Locomotor training after human spinal cord injury: a series of case studies. Phys} Ther, 80 (2000), pp. 688-700 
2 B. Dobkin, D. Apple, H. Barbeau, et al., Spinal Cord Injury Locomotor Trial Group. Weight-supported treadmill vs. over-ground training for walking after acute incomplete SCI. Neurology, 66 (2006), pp. 484-493

3 E.C. Field-Fote, S.D. Lindley, A.L. Sherman. Locomotor training approaches for individuals with spinal cord injury: a preliminary report of walking-related outcomes. J Neurol Phys Ther, 29 (2005), pp. 127-137

4 V. Dietz, G. Colombo, L. Jensen, L. Baumgartner. Locomotor capacity of spinal cord in paraplegic patients. Ann Neurol, 37 (1995), pp. 574-582

$5 \mathrm{~A}$. Wernig, S. Muller. Laufband locomotion with body weight support improved walking in persons with severe spinal cord injuries. Paraplegia, 30 (1992), pp. 229-238

6 A. Wernig, S. Muller, A. Nanassy, E. Cagol. Laufband therapy based on 'rules of spinal locomotion' is effective in spinal cord injury persons. Eur J Neurosci, 7 (1995), pp. 823-829

7 G. Colombo, M. Joerg, R. Schreier, V. Dietz. Treadmill training of paraplegic patients using a robotic orthosis. J Rehabil Res Dev, 37 (2000), pp. 693-700

8 S. Hesse, D. Uhlenbrock. A mechanized gait trainer for restoration of gait. J Rehabil Res Dev, 37 (2000), pp. 701-708

9 Healthsouth.com. HealthSouth's AutoAmbulator. ${ }^{\mathrm{Tm}}$ http://www.healthsouth.com/experiencehealthsouth/the-healthsouth-difference/leading-technology/autoambulator. Accessed September 26, 2011

10 T.G. Hornby, D.D. Campbell, D.H. Zemon, J.H. Kahn. Clinical and quantitative evaluation of robotic-assisted treadmill walking to retrain ambulation after spinal cord injury. Top Spinal Cord Inj Rehabil, 11 (2005), pp. 1-17

11 E. Swinnen, S. Duerinck, J.P. Baeyens, R. Meeusen, E. Kerckhofs. Effectiveness of robot-assisted gait training in persons with spinal cord injury: a systematic review. J Rehabil Med, 42 (2010), pp. 520-526

12 E.C. Field-Fote, K.E. Roach. Influence of a locomotor training approach on walking speed and distance in people with chronic spinal cord injury: a randomized clinical trial. Phys Ther, 91 (2011), pp. 48-60

13 M. Wu, T.G. Hornby, J.M. Landry, H. Roth, B.D. Schmit. A cable-driven locomotor training system for restoration of gait in human SCl. Gait Posture, 33 (2011), pp. 256-260

14 J.L. Emken, D.J. Reinkensmeyer. Robot-enhanced motor learning: accelerating internal model formation during locomotion by transient dynamic amplification. IEEE Trans Neural Syst Rehabil Eng, 13 (2005), pp. 33-39

15 J.L. Emken, R. Benitez, D.J. Reinkensmeyer. Human-robot cooperative movement training: learning a novel sensory motor transformation during walking with robotic assistance-as-needed. $J$ Neuroeng Rehabil, 4 (2007), p. 8

16 E.T. Wolbrecht, V. Chan, D.J. Reinkensmeyer, J.E. Bobrow. Optimizing compliant, model-based robotic assistance to promote neurorehabilitation. IEEE Trans Neural Syst Rehabil Eng, 16 (2008), pp. 286-297

17 N.D. Harada, V. Chiu, A.L. Stewart. Mobility-related function in older adults: assessment with a 6-minute walk test. Arch Phys Med Rehabil, 80 (1999), pp. 837-841

18 K. Berg, S. Wood-Dauphinee, J.I. Williams. The Balance Scale: reliability assessment with elderly residents and patients with an acute stroke. Scand J Rehabil Med, 27 (1995), pp. 27-36

19 R.W. Bohannon, M.B. Smith. Interrater reliability of a Modified Ashworth Scale of muscle spasticity. Phys Ther, 67 (1987), pp. 206-207

20 J.F. Ditunno, P.L. Ditunno. Walking Index for Spinal Cord Injury (WISCI II): scale revision. Spinal Cord, 39 (2001), pp. 654-656

21 R.L. Waters, R.H. Adkins, J.S. Yakura, I. Sie. Motor and sensory recovery following incomplete paraplegia. Arch Phys Med Rehabil, 75 (1994), pp. 67-72

22 C.A. McHorney, J.E. Ware, J.F. Rachel Lu, C.D. Sherbourne. The MOS 36-Item Short-Form Health Survey (SF36): III, tests of data quality, scaling assumptions and reliability across diverse patient groups. Med Care, 32 (1994), pp. 40-66

23 L.E. Powell, A.M. Myers. The Activities-specific Balance Confidence (ABC) Scale. J Gerontol A BiolSci Med Sci, 50A (1995), pp. M28-M34 
24 E.C. Field-Fote, S.D. Lindley, A.L. Sherman. Locomotor training approaches for individuals with spinal cord injury: a preliminary report of walking-related outcomes. J Neurol Phys Ther, 29 (2005), pp. 127-137

25 M. Wirz, D.H. Zemon, R. Rupp, et al. Effectiveness of automated locomotor training in patients with chronic incomplete spinal cord injury: a multicenter trial. Arch Phys Med Rehabil, 86 (2005), pp. 672-680

26 G. Scivoletto, A. Romanelli, A. Mariotti, et al. Clinical factors that affect walking level and performance in chronic spinal cord lesion patients. Spine, 33 (2008), pp. 259-264

27 T.G. Hornby, D.J. Reinkensmeyer, D. Chen. Manually-assisted versus robotic-assisted body weightsupported treadmill training in spinal cord injury: what is the role of each? PM R, 2 (2010), pp. 214-221

28 M. Lotze, C. Braun, N. Birbaumer, S. Anders, L.G. Cohen. Motor learning elicited by voluntary drive. Brain, 126 (2003), pp. 866-872

29 M. Lotze, L.G. Cohen. Volition and imagery in neurorehabilitation. Cogn Behav Neurol, 19 (2006), pp. 135140

30 L.L. Cai, A.J. Fong, C.K. Otoshi, et al. Implications of assist-as-needed robotic step training after a complete spinal cord injury on intrinsic strategies of motor learning. J Neurosci, 26 (2006), pp. 10564-10568

31 M.D. Ziegler, H. Zhong, R.R. Roy, V.R. Edgerton. Why variability facilitates spinal learning. J Neurosci, 30 (2010), pp. 10720-10726

32 C.M. Kim, J.J. Eng, M.W. Whittaker. Level walking and ambulatory capacity in persons with incomplete spinal cord injury: relationship with muscle strength. Spinal Cord, 42 (2004), pp. 156-162

33 E.C. Field-Fote. Combined use of body weight support, functional electric stimulation, and treadmill training to improve walking ability in individuals with chronic incomplete spinal cord injury. Arch Phys Med Rehabil, 82 (2001), pp. 818-824

34 P.H. McCrea, J.J. Eng, A.J. Hodgson. Time and magnitude of torque generation is impaired in both arms following stroke. Muscle Nerve, 281 (2003), pp. 46-53

35 C.I. Renner, P. Bungert-Kahl, H. Hummelsheim. Change of strength and rate of rise of tension relate to functional arm recovery after stroke. Arch Phys Med Rehabil, 90 (2009), pp. 1548-1556

36 K.E. Norman, A. Pepin, H. Barbeau. Effects of drugs on walking after spinal cord injury. Spinal Cord, 36 (1998), pp. 699-715

Supported by the Paralyzed Veterans of America Research Foundation (grant no. 2552), and, in part, by the Falk Foundation.

No commercial party having a direct financial interest in the results of the research supporting this article has or will confer a benefit on the authors or on any organization with which the authors are associated.

In-press corrected proof published online on Mar 29, 2012, at www.archives-pmr.org. 